\title{
El proceso productivo del videojuego: fases de producción
}

\author{
Ana Ma Manrubia Pereira \\ Universidad Complutense de Madrid \\ amanrubia@edu.xunta.es
}

\begin{abstract}
Resumen:
El videojuego como una de las incipientes industrias culturales se caracteriza en su diseño por la confluencia de dos grandes ámbitos de creación, el audiovisual y la informática. Sus peculiaridades como producto hacen que sea necesario el tránsito por unas fases concretas y determinantes de producción.
\end{abstract}

Palabras clave: Diseño del videojuego; producción audiovisual; recursos informáticos; industria cultural.

\section{The production process of the game: production phases}

\begin{abstract}
:
The game as one of the emerging cultural industries in its design is characterized by the confluence of two major areas of creation, audiovisual and computer. Its peculiarities as product cause the traffic by specific determinants and production phases necessary.
\end{abstract}

Key Words: Game design; audiovisual production; computer resources; cultural industry

\section{Referencia normalizada:}

Manrubia Pereira, A. M. (2014): El proceso productivo del videojuego: fases de producción. Historia y Comunicación Social. Vol. 19. Núm. Especial Marzo. Págs. 791-805.

Sumario: Introducción. 2. Método. 3 La industria del videojuego 4. El proceso de producción de videojuegos. 4.1 Fase de preproducción. 4.2 Fase de producción. 4.2.1 Diseño del juego. 4.2.2 Diseño artístico. 4.2.3 Diseño mecánico. 4.2.4 Motor del juego. 4.2.5 Diseño técnico. 4.2.6 Implementación. 4.2.7 Pruebas Alpha. 4.2.8 Pruebas Beta. 4.2.9 Gold Master. 4.3 Posproducción. 5. Conclusiones. 6. Bibliografía. 7. Notas al pie

\section{Introducción}

Los videojuegos no dejan de ser recursos informáticos pero muy próximos en cuanto a consumo y producción al entorno audiovisual. El sistema de producción del audiovisual tiene clara relación con gran parte de las fases de desarrollo del video- 
juego, a pesar de ser considerado un software más, no existe una metodología común y propia para su diseño y desarrollo.

Antes de entrar de lleno en el proceso de producción del videojuego es importante tener presente la situación de este entorno como industria y cuál es su perfilado en España.

El desarrollo del juego, a lo largo de su ciclo de vida, se puede asemejar al de una película de cine, pudiéndose segmentar en tres fases ampliamente diferenciadas: Pre-Producción, Producción y Post-producción, cada una con sus etapas características (Bethke, 2003), a pesar de que son las propias compañías las que fijan cuál será su filosofía de trabajo a lo largo de la creación de un juego.

\section{Método}

En primer lugar establecemos una radiografía del estado de la industria del videojuego con las tendencias más actuales a nivel internacional y la plasmación directa en el entramado español. A continuación realizamos una exposición de las distintas fases por las que pasa la producción de videojuegos y las equipos de profesionales que en cada una entran en juego; como cierre se plantea la clara vinculación existente entre el audiovisual y la informática y cómo sólo a través de la optimización de los recursos disponibles en cada una de estas áreas se podrá llegar a una estructura industrial y productiva ideal para una industria cultural como el videojuego.

\section{La industria del videojuego}

Las industrias culturales clásicas ven como los videojuegos toman posiciones y se consolidan como un sector en alza y con una posición claramente predominante en este entramado industrial. El campo del videojuego ya no es sólo una industria que aporta importantes beneficios sino que se convierte en objeto de estudio desde metodologías y puntos de vista diversos. (Aguado, 2008).

En España el mercado de los videojuegos se ha visto influido por la formación y consolidación de grupos multinacionales que concentran las cuotas más importantes de la demanda. Esta tendencia internacional ha marcado el desarrollo de la industria de la comunicación desde los años 90 y no es exclusiva del sector de los games.

Se manifiesta en la escasa cantidad de actores que operan en el mercado y en el crecimiento de estos en detrimento de las empresas con menor músculo financiero, que han sido incapaces de asumir el reto de la internacionalización. Rodríguez,V.\& Pestaño,J.M. 2012) 
Las multinacionales copan el sector y si en algún momento hubo alguna pequeña industria a nivel español que intentaba hacerse hueco en el mercado ésta acabó siendo absorbida siguiendo la tendencia del liberalismo predominante para poder hacer frente al reto de la internacionalización.

La demanda que se genera en torno a la industria del videojuego ha de ser cubierta en España de manera casi absoluta por empresas norteamericanas y japonesas.

En este contexto tienen lugar distintas estrategias de concentración empresarial. La integración vertical ${ }^{1}$ es una de ellas y se basa en el control absoluto de las diferentes fases del proceso de producción y comercialización por una misma corporación (Sánchez-Tabernero, 2000).

A medida que la tecnología y soporte técnico que envuelve al videojuego mejora y crece se hace más y más complicado que una industria del tamaño de la española se sostenga por sí misma. María Jesús López, cofundadora de Erbe (una de las más importantes desarrolladoras y distribuidoras españolas de videojuegos en la década de 1980), explica que el éxito que tuvieron los juegos elaborados en este país en la época del Spectrum, Amstrad y Comodore remitió porque llegaron las consolas. Con ellas, la necesidad de recursos económicos para desarrollar videojuegos fue mucho mayor y ya no eran suficientes los equipos de trabajo pequeños con los que contaban las empresas punteras de esa etapa. Ahora se necesitan, explica, equipos de alrededor de doscientas personas para poder elaborar un producto que puede tardar en salir dos años al mercado. Además dichos equipos deben ser interdisciplinares, porque tienen que elaborar aplicaciones en línea, efectos especiales, 3D y otros muchos añadidos con los que ni se soñaba hace tres décadas. Según la empresaria, son muy pocas las compañías españolas que pueden asumir ese esfuerzo económico (Retroacción, 2009).

La concentración empresarial vendrá generada no sólo por la obligación de contar con fuertes inversiones no sólo en términos tecnológicos sino también de personal, y por la necesidad de disminuir el riesgo de fracaso comercial de los grandes lanzamientos. Se trata al igual que otros productos audiovisuales de producciones de alto riesgo donde la rentabilidad no está ni mucho menos asegurada.

\section{El proceso de producción de videojuegos}

Como base de trabajo consideraremos como producción el proceso en el que se obtienen tangibilidades y por el contrario en la preproducción deberían aparecer aspectos no tangibles o poco elaborados y que tienen más que ver con la planificación del juego, todo aquello que en el ocio electrónico se conoce como "diseño conceptual". 
Sin lugar a dudas el proceso más costoso, por el número de personas a las que involucra, es el Diseño del juego junto con el Diseño técnico (ambas conforman la fase tradicional de Diseño de Sofware) y se incluyen en la fase de producción

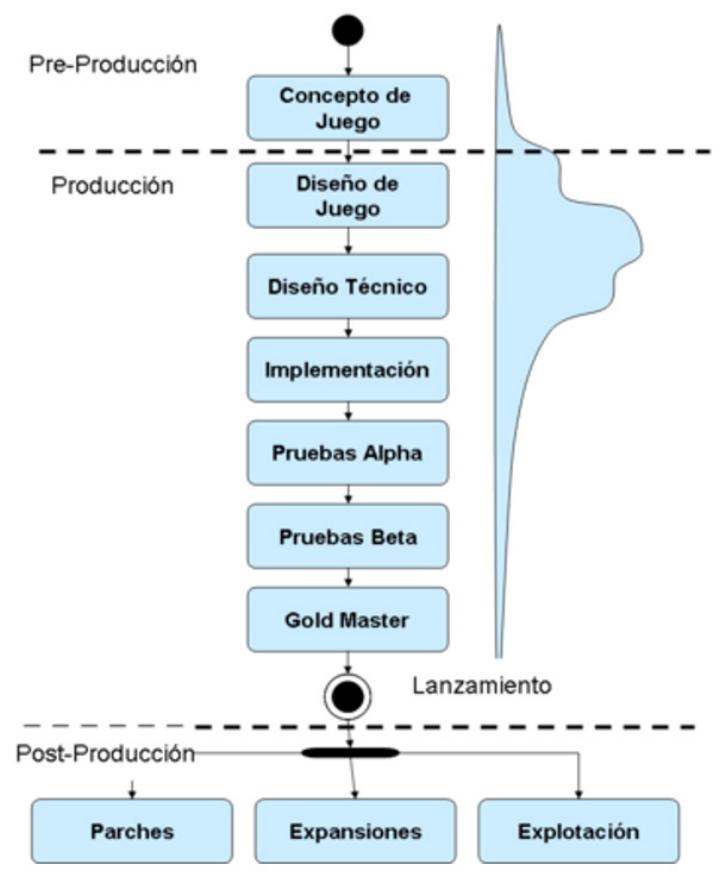

\subsection{Fase de preproducción}

En esta fase de define el juego, la concepción general con sus aspectos más relevantes y los términos en los que se llevará a cabo su materialización.

\section{Aspectos que conforman el videojuego}

Género

Historia

Bocetos
Género o géneros al que pertenece el videojuego y que marcará necesariamente su diseño.

Esbozo de la trama o historia que se contará a través del videojuego. Storyline/storytelling ( qué contar y cómo)

Diseños preliminares de personajes, espacios, músicas, ambientaciones.. 
Gameplay

(Rouse III, 2005).
Es la esencia o naturaleza del videojuego, incluye la interactividad. Se define cómo se va a jugar, qué podremos hacer durante el juego y cómo se van a ir modificando los entornos o ambientaciones y cuál va a ser la curva de desarrollo del jugador. (Salen \& Zimmerman, 2003)

Esta fase concluye con una primera versión del Game Design Document (Bethker, 2003) a manos del equipo creativo y que será fundamental para el diseño del videojuego y la producción en sí misma.

\begin{tabular}{|c|c|}
\hline \multicolumn{2}{|c|}{ Elementos que incluye un GDD (Game Design Document) } \\
\hline Género & Clasificación según su naturaleza \\
\hline Jugadores & $\begin{array}{c}\text { Modalidad de juego (individual o colectivo). Si es } \\
\text { multijugador, si éstos son humanos o entra la máquina. }\end{array}$ \\
\hline Historia & $\begin{array}{c}\text { Resumen de la historia del juego, de qué trata y cómo lo } \\
\text { trata. }\end{array}$ \\
\hline Look and Feel & $\begin{array}{c}\text { A partir de los bocetos se define el aspecto gráfico } \\
\text { y artístico del juego, colores, temas dominantes, } \\
\text { musicalidad, técnicas de diseño 3D o 2D, posiciones de } \\
\text { cámaras, etc. }\end{array}$ \\
\hline Interfaz de Usuario & $\begin{array}{c}\text { Se define como la manera en la que interactuará el } \\
\text { jugador con el juego y con qué mecanismos contará para } \\
\text { ello. }\end{array}$ \\
\hline Objetivos & $\begin{array}{c}\text { Cuáles son las metas del juego, de acuerdo a la historia } \\
\text { de éste. }\end{array}$ \\
\hline Reglas & $\begin{array}{c}\text { Qué cosas podemos hacer y cómo vamos a dejar que se } \\
\text { hagan. }\end{array}$ \\
\hline Características & $\begin{array}{c}\text { Especificaremos las principales características de cada } \\
\text { personaje del juego y de los elementos que intervienen } \\
\text { en éste. }\end{array}$ \\
\hline Diseño de Niveles & $\begin{array}{c}\text { Describiremos qué niveles, según la historia o dificultad, } \\
\text { tenemos, cómo serán éstos, cuántos serán, y qué } \\
\text { dificultad y retos se plantearán en cada uno de ellos. }\end{array}$ \\
\hline Presupuesto & $\begin{array}{c}\text { Estableceremos los requerimientos técnicos de equipo } \\
\text { que necesitará nuestro juego para poder ejecutarse. }\end{array}$ \\
\hline Marketing & $\begin{array}{c}\text { Un mal estudio de marketing puede tirar por tierra la } \\
\text { inversión millonaria de un producto de este tipo, es } \\
\text { fundamental el trazado de las líneas de publicidad para } \\
\text { nuestro juego. }\end{array}$ \\
\hline pijamos el presupuesto aproximado que necesitaremos a buen fin nuestro juego. \\
\hline
\end{tabular}

\subsection{Fase de producción}

Al equipo primigenio que ha llevado a cabo la planificación inicial del juego se le suma el resto de la plantilla asociada a la producción del juego. Es una fase dificultosa por la confluencia de actividades diversas. En ella participan multitud de profesiona- 
les de ámbitos muy específicos, con clara especialización en función de las subfases en las que se ubiquen. Esta complejidad obliga a distinguir varias etapas dentro de la producción en sí.

\subsubsection{Diseño del juego}

Es el momento de especificar los elementos que compondrán el juego, dando una idea clara a todos los miembros del grupo desarrollador de cómo son. Se da finalizado el GDD diseñando en profundidad todos los aspectos anteriormente especificados y que en fase de preproducción únicamente se habían perfilado.

\subsubsection{Diseño Artístico}

El apartado de diseño trabaja elementos que tienen que ver con la "apariencia" del juego en sí, contenidos que van a tener una plasmación evidente en el "físico" del videojuego:

- Historia: se crea la Biblia donde se recogen todas las historias de los personajes, del mundo donde sucede el juego, de su pasado y de los personajes secundarios que aparecen, creando el hilo argumental completo, con todos los detalles.

- Sonido: Se diseñan todos los elementos sonoros de nuestro juego: voces, ambiente, efectos y música. Se pone en funcionamiento el engranaje sonoro.

- Interfaz: Se describe la forma en que se verán los elementos GUI (Graphical User Interface) y HUD (Head-Up Display), mediante los cuales el usuario interactuará con el juego.

- Gráficos: Dependiendo de si el juego es 2D o 3D se diseñarán los elementos gráficos como los sprites, tiles, modelos $3 \mathrm{D}$, cámaras, luces, etc. o cualquier otro elemento gráfico susceptible de ser utilizado en el juego.

Con estos cuatro elementos, historia, sonido, interfaz y gráficos, se genera un documento marco conocido como Biblia del Arte del juego y en la que se compendian todos los aspectos relacionados con la "forma" artística de nuestro juego, esos elementos que lo harán diferente a otros en el mercado

\subsubsection{Diseño Mecánico.}

En esta fase se marcan las pautas de interacción con el juego, las normas internas y el tipo de comunicación que debe darse en caso de que el destino del juego sea el entorno on line. Los detalles cobran vida en este punto con el diseño de reacciones y comportamientos que darán vida a cada uno de los personajes.

El diseño de Inteligencia Artificial (IA) del juego y el motor asociado a ella deben darse ahora $\mathrm{y}$, evidentemente antes de que el motor de juego sea materializado. También se diseña el Motor Físico, encargado de generar diversos aspectos físicos 
de los elementos y del mundo donde se lleva a cabo el juego (explosiones, disparos, caídas, etc.).

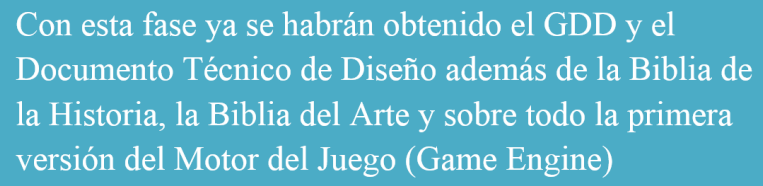

4.2.4 Motor del Juego.

Es el elemento más importante, y se puede decir que es la parte fundamental de este proceso tan costoso y duradero. El Motor del Juego hace referencia a una serie de rutinas que permiten la representación de todos los elementos del juego (Bethke, 2003), (Rollings \& Morris, 2003). El arte y los guiones del juego no funcionarán jamás sin un motor del juego.

Es aquí donde debemos controlar cómo se representan los elementos del juego y cómo se interactúa con ellos (Martín \& Ballejo, 2012). Gestionaremos la IA del juego, los sonidos asociados a cada elemento del juego en cada momento además del grafismo vinculado directamente a estos elementos. El Motor del Juego es el equivalente a la conjunción del Motor Gráfico, Motor de Sonido, Gestor de IA y Motor Físico, además de las reglas necesarias para crear el universo completo de nuestro juego y facilitar la inmersión del gamer.
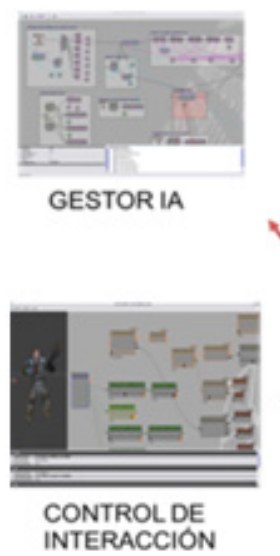

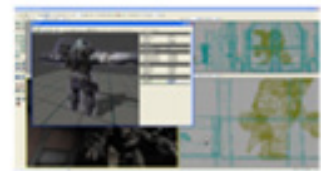

MOTOR GRÁFICO
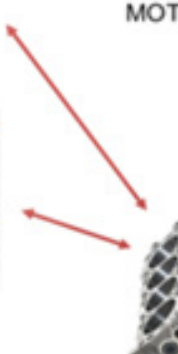

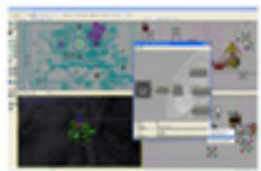

MOTOR DE SONIDO

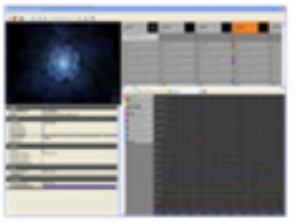

MOTOR FISICO

Fuente: González Sánchez, 2010 


\subsubsection{Diseño Técnico}

Para poder disfrutar el videojuego como forma de ocio o industria cultural precisamos del soporte para el que fueron creados, precisamos de la "aplicación" informática que sustente la historia que hay detrás del videojuego. Esa aplicación tiene una vinculación clara con el entorno informático ( sea cual sea su destino: plataformas móviles, ordenadores, juegos on line...), muy especialmente en esta etapa donde esa relación cobra una evidencia reseñable, aquí se asemeja con la producción de cualquier otro software, su diseño es similar, es donde se trata el juego como un verdadero producto de software.

Se generaran los distintos tipos de flujos de relación, los diagramas que describan el funcionamiento estático y dinámico, la interacción con los usuarios y los diferentes estados que atravesará el videojuego como software. A partir de aquí se generará nuestro Documento de Diseño.

\subsubsection{Implementación.}

La etapa de implementación tiene como misión organizar de manera coherente todas y cada una de las piezas elaboradas y planificadas hasta el momento, generando un engranaje perfecto que precisa del motor de juego previsto para que todo funcione.

No es un proceso creativo en sí mismo pero a pesar de ello tiene una importancia crucial: se finalizan contenidos, se perfilan detalles, se corrigen errores juego y utilizando, por supuesto, el motor de juego previsto. Se pueden desechar ideas que son buenas, pero que no encajan al final del juego y corregir imprevistos.

Una vez aunadas las grandes etapas en las que terminan por mezclarse lo técnico, lo artístico y lo mecánico, el producto se puede dar a conocer... es la puesta en marcha de nuestro producto en el mercado. El producto empezará a formar parte de un entorno competitivo, lleno de múltiples posibilidades, será necesario generar en el potencial "consumidor" la necesidad de consumirlo y esto se consigue, como no, con una adecuada estrategia de márketing que muy probablemente ya se haya empezado a forjar en fases iniciáticas del proyecto, cuándo se entra a valorar el público objetivo y las posibilidades de implantación en el mercado.

\subsubsection{Pruebas Alpha}

Durante las pruebas Alpha o Code Complete ya contamos con un producto terminado. En el desarrollo de productos culturales será preciso pasar, necesariamente, por el periodo de testeo del resultado, será preciso poner en práctica toda una serie de pruebas que muestren que el círculo de producción se puede dar por concluido y lo que fue un proyecto ya se ha convertido en producto, ya puede ser lanzado al mercado. Un pequeño grupo, involucrado en el diseño y desarrollo del juego, pone a prueba el producto buscando errores o matices que deban ser corregidos. Uno de los aspectos fundamentales que deben ser tenidos en cuenta es la jugabilidad ${ }^{2}$, que será valorada según diversos criterios ya establecidos por las empresas del sector. 


\subsubsection{Pruebas Beta}

En las pruebas Beta o Content Complete se dan por concluidas todas las variaciones del contenido (decorado de misiones, gráficos, textos en diferentes idiomas, doblaje, etc.). En este caso las pruebas las realizan profesionales externos al equipo de trabajo vinculado directamente con el juego, ya sean externos a la empresa o sólo al proyecto, intentando conseguir que el videojuego vea la luz con la menor cantidad posible de defectos. Es también el momento en el que se comprueba que, a nivel legal, los contenidos del juego se adapten a las normativas de los países donde se va a publicar, no hay una unificación legal en estos contenidos y esto deberá ser tenido en cuenta al plantearse las posibilidades de distribución y si nuestro interés está en zonas especialmente complicadas en cuanto a la estricta legislación que marca fundamentalmente contenidos, deberemos valorar la posibilidad de llevar a cabo varias versiones de nuestro producto.

\subsubsection{Gold Master}

Es la copia definitiva, con esta denominación es como se conoce al juego que se publicará y se enviará a la fábrica para su producción con todo el contenido de arte (diseño de portada, caja, etc.) y manuales de usuario. Es el equivalente a la copia máster en el audiovisual. A partir del Gold Master se prepara el tiraje de copias necesarias para la distribución.

Hemos llegado a un momento en el que la campaña de publicidad debe ser máxima, los medios especializados deben conocer nuestro producto y hablar sobre él si queremos que nuestro trabajo, en forma de videojuego, funcione en el/los mercado/s (Bethke, 2003).

\subsection{Posproducción}

El proceso vital del videojuego no termina con su puesta en el mercado, será preciso llevar a cabo el seguimiento oportuno para valorar si se está consiguiendo explotar todas sus posibilidades y dar respuesta también al comportamiento que el mercado ha tenido en relación con nuestro producto y que puede hacer que modifiquemos nuestras estrategias en uno u otro sentido. La campaña de marketing ya está en marcha y si hasta el momento no hemos podido cerrar todos los acuerdos deseados este es el momento de concretar nuevas fórmulas de expansión, posibilidades en distintos mercados, nuevas fórmulas de explotación.

El mercado obliga y teniendo en cuenta el momento en el que se encuentra el el mercado en general y las peculiaridades de la industria del videojuego en España en particular, las empresas suelen marcar sus líneas de trabajo en torno a dos grupos e profesionales: por un lado el equipo de producción, que irá dotando de vida el proyecto, y, por otro lado, el equipo de financiación, que se encargarán básicamente de que el sueño ideado por producción sea posible. Dadas las dificultades que hoy por hoy existen para sacar adelante un proyecto audiovisual, sea este del tipo que 
sea, los implicados se ven obligados a que la búsqueda de financiación inicial y su consecución marque la continuación o no de algunos proyectos. Dentro de la industrias culturales el videojuego es peculiar, entre otras cosas, porque requiere de una considerable inversión previa; desde la preproducción inicial se ha de contar con una financiación considerable para seguir dando pasos en el desarrollo del producto ${ }^{3}$.

Todas estas etapas están cubiertas con un conjunto de profesiones que se cruzan en distintos departamentos en un organigrama de funcionamiento que si bien puede variar dependiendo de los casos podría contar con una estructura similar a esta:

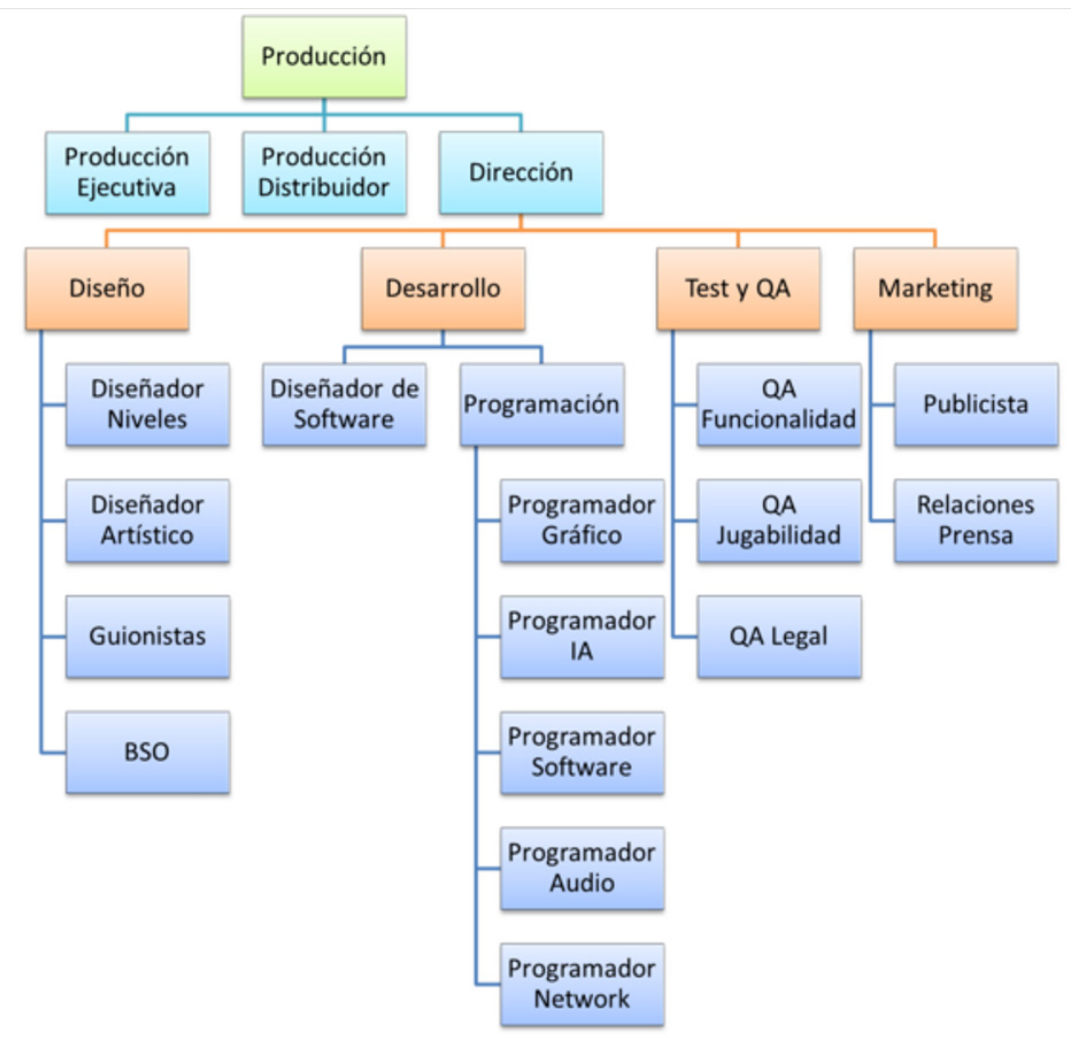

Ejemplo de estructuración de un equipo de producción de un videojuego Fuente: Bethke, 2003.

\section{Conclusiones}

El modelo que se ha tratado de recoger en el desarrollo del artículo es un modelo en cascada, un modelo ya recogido por los clásicos (Royce, 1970) y que tiene su base en el que la creación del software en este caso se produce por el desarrollo siguiendo un fluir constante hacia abajo. Las desventajas de este sistema de trabajo son varias entre otras la lentitud de su proceso, parte de fases estancas y dependientes, no permite el 
trabajo en paralelo de distintos equipos, sin embargo la industria da un paso más y a pesar de ser este el método "académico" de funcionar los profesionales de los videojuegos prefieren acercarse más al modo de trabajo en el audiovisual que en el entorno informático y a pesar de mantener fases y conductas absolutamente necesarias por la peculiaridad del producto que tienen entre manos optan por el solapamiento en el trabajo de distintos equipos algo que agiliza en gran media los procesos y que es habitual en el entorno cinematográfico o televisivo, por ejemplo. Este afán pragmático busca el no dilatar en exceso la consecución del producto final aplicando, por ejemplo, entre otros, los Procesos Ágiles de desarrollo de software de Keith (Keith, 2009), teniendo en cuenta que los contenidos audiovisuales son, en muchos casos, perecederos, su vida útil está condicionada a modas, hábitos, tendencias del mercados, tecnologías incipientes...

Con esto se quiere dejar claro que no hay un modelo único y válido para la producción de videojuegos sino que si bien existen unas fases muy claras como en cualquier producción audiovisual y que necesariamente hay que respetar, el cómo se establezcan los tiempos o las comunicaciones entre distintas fases va a depender mucho del modo de trabajar de cada empresa o de cada desarrollador del proyecto en cuestión.

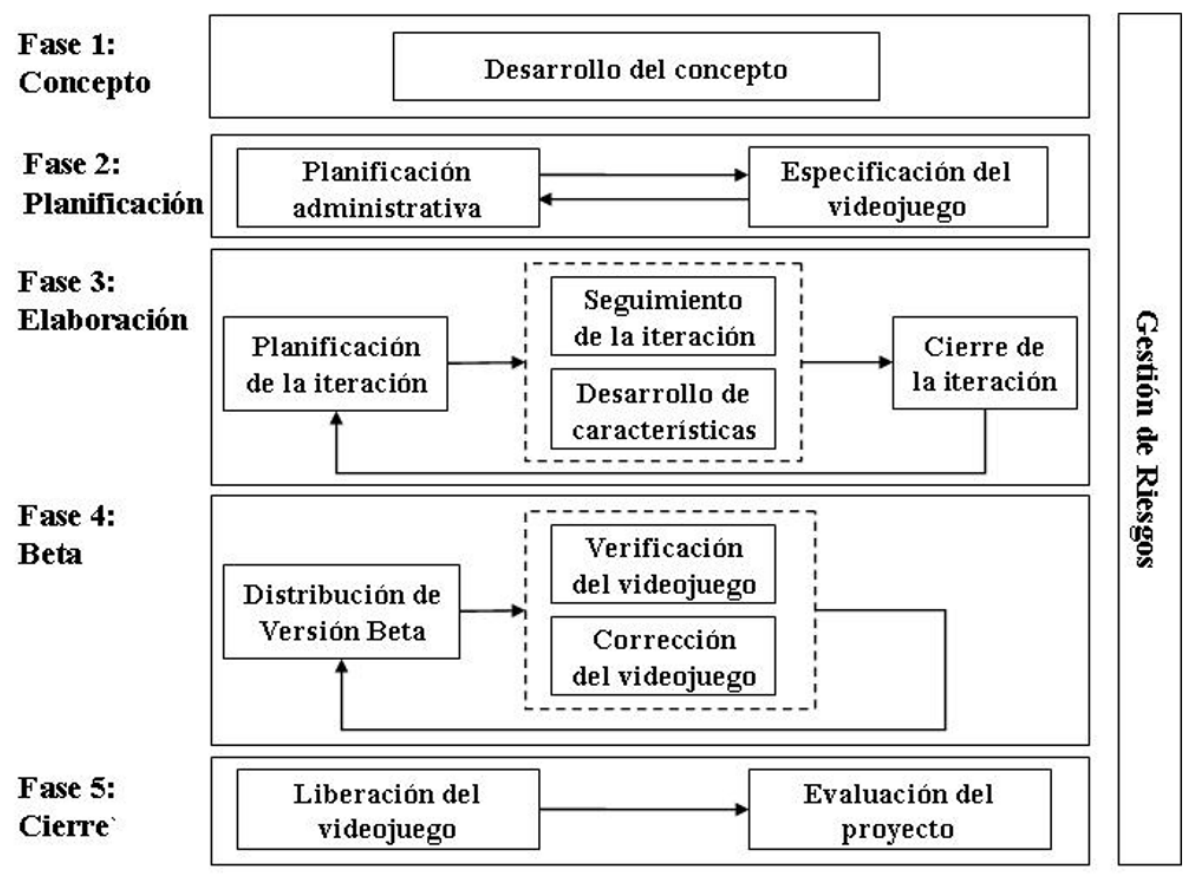

Fases del proceso de producción. Fuente:Coppes, Mesa...,2009

Si tenemos en cuenta entonces la interrelación fluida entre los dos entornos de trabajo que obligatoriamente entran en juego aquí podemos derivar estructuras de trabajo mucho más abiertas e intercomunicadas que flexibilizan y agilizan considerablemente la producción de videojuegos aun respetando sus peculiaridades y fases. 


\section{Bibliografía}

\subsection{Artículos en publicación web}

ADESE (Asociación Española de Distribuidores y Editores de Software de Entretenimiento): Anuario Adese 2003, 2004, en línea en http://www.adese.es/pdf/anuario-memoria-2003.pdf [consultado el 20- 01-2012].

ADESE (Asociación Española de Distribuidores y Editores de Software de Entretenimiento): Anuario Adese 2005, 2006, en línea en http://www.adese.es/pdf/anuario-memoria-2006.pdf [Consultado el 17-08- 2010]

ADESE (Asociación Española de Distribuidores y Editores de Software de Entretenimiento): Anuario Adese 2009, 2010, en línea en http://www.adese.es/pdf/Anuario2009aDeSe.pdf [Consultado el 25-10-2010]

ADESE (Asociación Española de Distribuidores y Editores de Software de Entretenimiento): Anuario Adese 2010, 2011, en línea en http://www.adese.es/pdf/anuario2010/ANUARIO2010.pdf [Consultado el 20-01-2012].

ADESE (Asociación Española de Distribuidores y Editores de Software de Entretenimiento)(2011): El videojugador español: perfil, hábitos e inquietudes de nuestros gamers, en línea en http://www.adese.es/pdf/EstilodeVidayvaloresdelosjugadoresdevideojuegos_resumenpresentacion.pdf [Consultado el 20-01-2012].

AETIC (Asociación de Empresas de Electrónica, Tecnologías de la Información y Telecomunicaciones de España) (2011): La industria de los contenidos digitales 2010, Observatorio Industrial del Sector de Electrónica, Tecnologías de la Información y Telecomunicaciones, Madrid.

AMETIC (2012): Informe de la industria de contenidos digitales 2011, Ametic, en línea en: http://www.cedro.org/docs/documentos/informe_contenidosdigitales2011.pdf?Status=Master.

DÍAZ SOLOAGA, Paloma (2006): "Efectos del uso del videojuegos en niños y adolescentes en España y EEUU", en Icono, 14, n. ${ }^{\circ}$ 7, en línea en http://www. icono14.net/revista/num7/articulos/paloma\%20diaz.pdf. [Consultado el 7-032012].

GFK EMER AD-HOC RESEARCH (2009): Usos y hábitos de los videojugadores españoles, Adese, Madrid, en línea en http://www.adese.es/pdf/PPThabitos122009.pdf [Consultado el 14 -08-2010].

\subsection{Libros:}

AGUADO, Guadalupe; GALÁN, Javier; FERNÁNDEZ-BEAUMONT, José y GARCÍA, Luis José (2008): Organización y gestión de la empresa informativa, Síntesis, Madrid.

CASTELLS, Manuel (2009): Comunicación y poder, Alianza Editorial, Madrid.

GONZÁLEZ SANCHEZ, J.L (2010): Jugabilidad. Caracterización de la experiencia del jugador de videojuegos. Universidad de Granada 
LEVIS, Diego (1997): Los videojuegos: un fenómeno de masas. Qué impacto produce sobre la infancia y la juventud la industria más próspera del sistema audiovisual, Paidós, Buenos Aires.

MARTÍN ANGELINA, Cleto y BALLEJO, David (2012). Desarrollo de videojuegos 1: Arquitectura de motor de videojuegos. Universidad de Castilla la Mancha.

RODRÍGUEZ, V., \& PESTANO, J. M. (2012). Los videojuegos en España:una industria cultural incipiente. Ambitos, 361-379.

ROUSE III, Richard (2005). Game Design: Theory and Practice.Wordware Publishing. Estados Unidos.

SALEN \&ZIMERMAN (2004): Rules of Play: Game Design Fundamentals.The Massachusetts Institute of Tecnology Press. London.

SÁNCHEZ TABERNERO, Alfonso (2000): Dirección estratégica de empresas de comunicación. Cátedra. Madrid.

WYMAN, Oliver (2009): Libro blanco de los contenidos digitales en España 2008. Ministerio de

Industria, Turismo y Comercio, red.es y ONTSI, Madrid, 2009

\subsection{Artículos}

BARANOWSKI, Tom; BUDAY, Richard; THOMPSON, Debbe; BARANOWSKI, Janice. (2009): "Playing for Real: Video Games and Stories for Health-Related Behavior Change", en American Journal of Preventive Medecine, vol. 34, ${ }^{\circ} 1$. pp. 74-82.

CHECA GODOY, Antonio (2009): "Hacia una industria española del videojuego", en Comunicación, n. ${ }^{\circ}$ 7, vol.1, pp. 177-188.

COPPES, Ariel; MESA, Gustavo y otros (2009). "Una metodología para el desarrollo de videojuegos". Simposio Argentino de Ingeniería de Sofware. p.174

EVANS, Elizabeth (2008): "Character, Audience Agency and Transmedia Drama", en Media, Culture and Society, vol. 30, n 2, pp. 197-213.

GROS, Begoña; BERNAT, Antonia (2008): "El aprendizaje de competencias de alfabetización digital a través de los videojuegos", en Aula de Innovación Educativa, vol. $15, \mathrm{n}^{\mathrm{o}} 176$, pp. 12-16.

KEITH, Clinton (2009). Advanced scrum and agile development. In Game Developer Conference, Marzo .

MORENO, Pedro Manuel(2002): "El reto del videojuego on line: mercado creciente con escasa industria", en BUSTAMANTE, Enrique (coord.): Comunicación y cultura en la era digital. Industrias, mercados y diversidad en España, Gedisa, Barcelona.

RETROACCIÓN (Asociación para el estudio y divulgación de la informática clásica): Mesa redonda "Producción y distribución del videojuego en España: de los pioneros a la industria actual", Madrid, 2009, en línea en: http://retroaccion.org/ mesa-redonda-produccion-y-distribucion-del-videojuego-en-espana-de-los-pioneros-la-industria-actual [consultado el 4- 02-2012].

SÁNCHEZ-TABERNERO, Alfonso: Dirección estratégica de empresas de comunicación, Cátedra, Madrid, 2000. 
AGUADO, Guadalupe; GALÁN, Javier; FERNÁNDEZ-BEAUMONT, José y GARCÍA, Luis José: Organización y gestión de la empresa informativa, Síntesis, Madrid, 2008

\section{NOTAS}

1 La integración es ascendente cuando la empresa comienza a controlar una fase posterior a la que le era propia (por ejemplo, la distribución), y descendente cuando establece su control en una fase anterior (como es el caso del suministro). Por otro lado, la estrategia de la integración multimedia hace referencia la presencia de un grupo en distintos canales o medios de comunicación, para ganar una cuota mayor de mercado y aprovechar las sinergias y la diversificación de canales o medios de comunicación, para ganar una cuota mayor de mercado y aprovechar las sinergias y la diversificación de riesgos. Esa estrategia es similar a la multisectorial, aunque en esta última existe una participación en empresas de distintos ámbitos, no solo de la comunicación. La integración internacional, finalmente, configura un escenario en el que las economías de escala permiten la presencia de un grupo en distintos países, aprovechando el know-how de cada ubicación geográfica (Aguado , 2008).

2 Definimos la jugabilidad como el conjunto de propiedades que describen la experiencia del jugador ante un sistema de juego determinado, cuyo principal objetivo es divertir y entretener "de forma satisfactoria y creíble" ya sea solo o en compañía. Los atributos se suelen utilizar para caracterizar la jugabilidad son: a) Satisfacción: Agrado o complacencia del jugador ante el videojuego y el proceso de jugarlo. b) Aprendizaje: Facilidad para comprender y dominar el sistema y la mecánica del videojuego, es decir, los conceptos definidos en el Gameplay/Game Mechanic del juego: objetivos, reglas y formas de interaccionar con el videojuego.c) Efectividad: Tiempo y recursos necesarios para ofrecer diversión al jugador mientras éste logra los objetivos propuestos en el videojuego y alcanza la meta final de éste. d) Inmersión: Capacidad para creerse lo que se juega e integrarse en el mundo virtual mostrado en el juego. e) Motivación: Característica del videojuego que mueve a la persona a realizar determinadas acciones y a persistir en ellas para su culminación. f) Emoción: Impulso involuntario originado como respuesta a los estímulos del videojuego, que induce sentimientos y que desencadena conductas de reacción automática. g) Socialización: Atributos que hacen apreciar el videojuego de distinta manera al jugarlo en compañía (multijugador), ya sea de manera competitiva, colaborativa o cooperativa.

3 A diferencia del cine, por ejemplo, en el que el coste mayoritario lo encontramos en la fase de producción o rodaje, la planificación apenas requiere presupuesto, más allá de unos costes administrativos básicos. En el entorno del videojuego la financiación va a ser fundamental desde el principio, con costes asumidos y adheridos a cada etapa.

\section{La autora}

Ana $\mathrm{M}^{\mathrm{a}}$ Manrubia Pereira, licenciada en Comunicación Audiovisual y Publicidad y Relaciones Públicas por la Universidad Complutense de Madrid. Doctorada por la Universidad Complutense con la tesis La imagen de la mujer en el cine de Pedro Almodóvar. Profesora de Educación Secundaria en la Familia Profesional de Imagen 
y Sonido, especializada en los módulos profesionales de Planificación de proyectos audiovisuales y Procesos de Realización de audiovisuales. Componente del grupo investigación CONCILIUM (UCM). Miembro de distintos grupos de trabajo relacionados con el análisis de la imagen y los nuevos contenidos audiovisuales. 